\title{
Intoxicação experimental por aflatoxina em bezerros ${ }^{1}$
}

\author{
Felipe Pierezan², José Carlos Oliveira-Filho², Priscila M. Carmo ${ }^{2}$, Adelina R. Aires ${ }^{3}$, \\ Marta L.R. Leal ${ }^{3}$, Tatiana M. Souza ${ }^{4}$, Carlos A. Mallmann ${ }^{5}$ e Claudio S.L. Barros ${ }^{6 *}$
}

\begin{abstract}
Pierezan F., Oliveira Filho J.C., Carmo P.M., Aires A.R., Souza T.M., Mallmann C.A. \& Barros C.S.L. 2012. [Experimental aflatoxin poisoning in calves.] Intoxicação experimental por aflatoxina em bezerros. Pesquisa Veterinária Brasileira 32(7):607-618. Departamento de Patologia, Universidade Federal de Santa Maria, Camobi, Santa Maria, RS 97105-900, Brazil. E-mail: claudioslbarros@uol.com.br

Two experiments were performed in order to determine the toxic effects of varying doses of aflatoxins in calves. Clinical, productive and pathologic aspects of affected calves were considered. In the first experiment, nine 2 to 4-month-old calves Holstein Friesian calves were fed, for two months, daily amounts corresponding to $1.5 \%$ of their body weight of a ration containing $500 \pm 100 \mathrm{ppb}$ of aflatoxins. Three calves of similar age and weight were used as controls and, except for being a ration free of aflatoxins, were kept in the same condition as the treated calves. In the second experiment, three 4-5-month old Holstein Friesian calves, were orally fed daily small parcels of a concentrate of aflatoxins diluted in $500 \mathrm{ml}$ of water corresponding to 1,250, 2,500 e 5,000 ppb of B1 aflatoxin (AFB1). A male 4-month-old Holstein Friesian calf was used as control. During all the experimental period of the first experiment, the weight gain of the calves receiving AFB1 was equivalent to that of the control group. In the first experiment no differences were observed between treated and control calves when the values of serum activity of aspartate transaminase (AST), serum albumin (SA), total serum protein (TP), and PVC, determined weekly, were compared. However there was a significant difference between treated and control groups in the serum activities of alkaline phosphatase (AP) and gamma glutamyl transferase when the serum sampled on the 63th day of the experiment was considered. During the whole experimental period and up to three weeks after the final of the experiment, no clinical signs or histopathological changes associated with the consumption of aflatoxins were observed in any of the calves of the first experiment. In the second experiment, clinical signs observed in three treated calves included loss of appetite, decrease in weight gain, and loss of weight. Jaundice, intermittent diarrhea, tenesmus and apathy were only observed in the calf receiving 5,000 ppb of AFB1. Due to these clinical signs the calf was euthanized. Increased activity of AF and GGT were observed in all the calves of the treated group during most part of the experimental period. A marked drop in the serum levels of SA was observed in the serum sampled on the 49 day of the experiment in the calf receiving the largest dose of aflatoxin. No changes were observed regarding PCV, TP, total bilirubin, direct bilirubin and in the serum activity of AST in any of the calves of the second experiment. Histopathological changes in intoxicated calves included bile duct proliferation, cytoplasmic vacuolar hepatocelular degeneration consistent with hepatocelular deposit of lipids, periportal to brid-
\end{abstract}

${ }^{1}$ Recebido em 29 de dezembro de 2011.

Aceito para publicação em 26 de janeiro de 2012.

Parte da Tese de Doutorado do primeiro autor. Financiado pelo CNPq, Projeto Universal 473493/2010-1.

${ }^{2}$ Programa de Pós-Graduação em Medicina Veterinária, área de concentração em Patologia Veterinária, Centro de Ciências Rurais (CCR), Universidade Federal de Santa Maria (UFSM), Camobi, Santa Maria, RS 97105900, Brasil.

\footnotetext{
${ }^{3}$ Laboratório de Endocrinologia e Metabolismo Animal, Departamento de Grandes Animais, CCR-UFSM, Santa Maria, RS.

${ }^{4}$ Bolsista do Programa Nacional de Pós Doutorado (PNPD) da CAPES junto ao projeto Aflatoxicose em Bovinos, Departamento de Patologia, CCR-UFSM, Santa Maria, RS.

${ }^{5}$ Laboratório de Análises Micotoxicológicas, CCR-UFSM, Santa Maria, RS.

${ }^{6}$ Departamento de Patologia, CCR-UFSM, Santa Maria, RS. *Pesquisador 1A do CNPq. Autor para correspondência: claudioslbarros@uol.com.br
} 
ging fibrosis, megalocytosis, subendothelial edema and fibrosis in terminal hepatic veins. Necropsy findings in the euthanatized calf which receive de largest doses of AFB1 included slight enlargement of the liver which was firm and diffusely light-yellow, mild ascites, and edema of the mesentery and of abomasal folds. Data stemmed from these two experiments allow to conclude that AFB1 doses of $500 \pm 100$ in the ration do not cause pathologic changes or decrease in productivity in calves kept in experimental conditions, but can be associated to minimal serum biochemistry; while AFB1 doses of 1.250, 2.500 e $5.000 \mathrm{ppb}$ in the ration cause chronic hepatic disease in calves in kept in experimental conditions.

INDEX TERMS: Diseases of cattle, mycotoxicosis, aflatoxina, aflatoxicosis, hepatic diseases, pathology.

RESUMO.- Foram realizados dois experimentos para determinar os efeitos tóxicos de diferentes doses de aflatoxinas em bezerros, considerando-se aspectos clínicos, produtivos e patológicos. No primeiro experimento, nove bezerros, Holandês, com 2-4 meses de idade, receberam ração contendo $500 \pm 100 \mathrm{ppb}$ de aflatoxina, na quantidade equivalente a $1,5 \%$ do peso vivo/dia, durante dois meses. Três bezerros de idade e peso semelhantes foram usados como controle e, exceto por terem recebido ração livre de aflatoxinas, foram mantidos nas mesmas condições. No segundo experimento, três bezerros, Holandês, com 4-5 meses de idade, receberam, por via oral, pequenas porções diárias de um concentrado de aflatoxinas, diluídas em $500 \mathrm{ml}$ de água, correspondendo a doses de $1.250,2.500 \mathrm{e}$ $5.000 \mathrm{ppb}$ de aflatoxina B1 (AFB1). Um bezerro, Holandês, 4 meses, macho, foi usado como controle. No primeiro experimento, o ganho de peso dos bezerros recebendo AFB1 foi equivalente ao do grupo controle durante todo período experimental. Nesse experimento não foram observadas alterações na atividade sérica da enzima aspartato transaminase (AST), nos níveis da albumina sérica (AS), da proteína total (PT) e no hematócrito, quando comparados os resultados semanais do grupo tratamento e controle. No entanto, observou-se diferença significativa nas atividades séricas das enzimas fosfatase alcalina (FA) e gama glutamil transferase (GGT) entre o grupo tratamento e o grupo controle, na coleta do 63ํ dia do experimento. Durante o período experimental, e três semanas após o término desse período, não foram observados sinais clínicos e alterações histopatológicas associadas ao consumo de aflatoxinas, em qualquer dos bezerros do grupo tratamento do primeiro experimento. No segundo experimento, sinais clínicos observados nos três bezerros intoxicados incluíram perda de apetite, diminuição do ganho de peso e emagrecimento. Icterícia, diarreia intermitente, tenesmo e apatia severa, foram observadas apenas no bezerro que recebia $5.000 \mathrm{ppb}$ de AFB1. Esses sinais clínicos foram a razão para eutanásia desse bezerro. Níveis alterados da atividade sérica de FA e GGT foram observados em todos os bezerros do grupo tratamento durante grande parte do período experimental. Queda acentuada do nível da AS sérica foi observada na coleta do 49 o dia do experimento no bezerro que recebia a maior dose de aflatoxina. Não foram observadas variações no hematócrito e na atividade sérica da AST, nem nos níveis séricos de proteína total, bilirrubina total e bilirrubina direta em qualquer dos bezerros desse experimento. Alterações histopatológicas nos bezerros intoxicados incluíram proliferação de ductos biliares, degeneração citoplasmáti- ca vacuolar consistente com acumulação hepatocelular de lipídios, fibrose periportal, ou em ponte, megalocitose, fibrose subendotelial das veias hepáticas terminais e edema. Achados de necropsia do bezerro recebendo a maior dose de AFB1 incluíram fígado levemente aumentado de tamanho, difusamente amarelo-claro e firme, discreta ascite, edema de mesentério e submucosa do abomaso. Os dados obtidos nesses experimentos permitem afirmar que doses de $500 \pm 100$ ppb de AFB1 não causam alterações patológicas e produtivas em bezerros em condições experimentais, mas podem estar associadas à mínimas alterações bioquímicas, enquanto doses de 1.250, 2.500 e 5.000 ppb de aflatoxina B1 causam doença hepática crônica em bezerros em condições experimentais.

TERMOS DE INDEXAÇÃO: Doenças de bovinos, micotoxicose, aflatoxina, aflatoxicose, doenças hepáticas, patologia.

\section{INTRODUÇÃO}

Aflatoxicose é uma doença hepática aguda, subaguda ou crônica de humanos e animais, causada por aflatoxinas, metabólitos tóxicos produzidos pelos fungos Aspergillus flavus e A. parasiticus. Esses fungos ubíquos e saprofíticos crescem em uma ampla variedade de grãos, rações para animais e alimentos para consumo humano, como amendoim, milho, algodão, sorgo, girassol, arroz e nozes. As quatro principais aflatoxinas são $B_{1}, B_{2}, G_{1}$ e $G_{2}$ e; dessas, a aflatoxina $\mathrm{B}_{1}$ é a mais comum e a mais tóxica (Kellerman et al. 2005).

A doença já foi documentada em humanos, primatas não-humanos, gatos, cães, roedores, aves, bovinos e búfalos pela ingestão de alimento contendo aflatoxina (Sastry et al. 1965, Vaid et al. 1981, Hussein \& Brasel 2001). A toxicidade das aflatoxinas varia dependendo da espécie animal considerada. Ruminantes estão entre os mais resistentes, uma vez que aflatoxinas são parcialmente degradados pela microbiota ruminal (Hussein \& Brasel 2001, Yiannikouris \& Jouany 2002). Assim, bovinos são classificados como medianamente sensíveis e ovinos como resistentes a aflatoxinas (Kellerman et al. 2005).

Surtos documentados de aflatoxicose em bovinos são raros. Nessa espécie, a doença geralmente não é tão fulminante quanto em suínos e segue um curso crônico ou subagudo após a exposição à aflatoxina por várias semanas ou meses (Kellerman et al. 2005), mas casos agudos já foram relatados em bovinos (McKenzie et al. 1981, Lafluf et al. 1989). A doença foi reproduzida em bovinos pela administração de doses orais de aflatoxina ou por administração de alimentos conta- 
minados por aflatoxina (Allcroft \& Lewis 1963, Garret et al. 1968, Lynch et al. 1970, 1971, Pier et al. 1976, Patterson \& Anderson 1982, Richard et al. 1983). No entanto, diferenças significativas nas doses consideradas como tóxicas para bovinos, assim como discrepâncias leves nas formas clínicas e achados patológicos dessa doença, são frequentes entre os vários estudos. A evolução das lesões hepáticas foi investigada em apenas um desses estudos experimentais, no qual as quantidades de aflatoxina ingeridas pelos bovinos não eram conhecidas (Allcroft \& Lewis 1963). Os aspectos epidemiológicos, clínicos e patológicos de um surto de doença hepática crônica em bezerros do Rio Grande do Sul, associada à ingestão de aflatoxina, foram recentemente relatados (Pierezan et al. 2010). Esses achados, em comparação com aqueles observados em outros surtos naturais e estudos experimentais descritos na literatura sobre essa doença, indicavam que era necessário um estudo sistemático para esclarecer vários pontos da intoxicação crônica por aflatoxina em bovinos.

0 objetivo deste trabalho foi descrever o resultado de experimentos realizados para determinar a influência de diferentes doses de aflatoxina sobre a produtividade de bezerros e os aspectos clínicos e patológicos da intoxicação nesses animais.

\section{MATERIAL E MÉTODOS \\ Animais de experimentação e métodos de administração da toxina}

Dois experimentos foram realizados no Laboratório de Patologia Veterinária, da Universidade Federal de Santa Maria. No primeiro, foram utilizados doze bezerros, machos, Holandês, com 2-4 meses de idade e pesos entre 44-93 kg. No período experimental (63 dias), os bezerros receberam ração contendo $18 \%$ de proteína, constituída por farelo de milho livre de aflatoxinas, farelo de soja, calcário calcítico e premix vitamínico. A quantidade de ração (equivalente a 1,5\% do peso vivo por dia) foi ajustada semanalmente de acordo com o peso dos bezerros. Na ração de nove bezerros do grupo tratamento foram adicionadas pequenas porções de um concentrado de aflatoxina B1 (AFB1), para obtenção de um nível médio de 500 ppb de AFB1. A adição de concentrado de toxina às rações foi realizada usandose um misturador vertical. As rações assim preparadas foram homogeneizadas por cerca de 10 minutos e acondicionadas por um período mínimo de três dias, para a uniformização da mistura. Três bezerros serviram como controle e receberam somente ração livre de aflatoxinas.

No segundo experimento foram utilizados quatro bezerros, machos, Holandês, com 4-5 meses de idade e pesos entre 92,8-145,8 kg. Durante o período experimental (63 dias), os bezerros receberam a mesma ração livre de aflatoxinas utilizada no primeiro experimento. A quantidade de ração (1,5\% do peso vivo) foi ajustada semanalmente. Os bezerros do grupo tratamento receberam diariamente, por via oral e diluídas em $500 \mathrm{~mL}$ de água, porções de um concentrado de AFB1 (arroz moído contendo altos níveis de aflatoxina), nas doses correspondente a 1.250, 2.500 e 5.000 ppb de AFB1. A quantidade de concentrado de toxina foi ajustada semanalmente conforme o aumento da quantidade de ração ingerida. Um bezerro, Holandês, 4 meses, macho, 137,8 kg, foi usado como controle.

Os bezerros utilizados em ambos experimentos foram everminados e mantidos em baias individuais por duas semanas antes do início dos experimentos para adaptação às instalações e a alimentação. Diariamente, as baias eram limpas e os animais avaliados quanto ao estado geral e o apetite. Durante todo experimento os bezerros de ambos experimentos receberam feno de tifton à vontade. Dados gerais dos bezerros e doses utilizadas nos experimentos são demonstradas no Quadro 1. - Amos experimentos foram aprovados pelo comitê de ética e experimentação animal da UFSM (Porcesso 23081.006997/2010-34).

\section{Método de produção da toxina}

O concentrado de AFB1 foi produzida pelo Instituto de Soluções Analíticas Microbiológicas e Tecnológicas (SAMITEC), a partir da cepa NRLL 2999 de Aspergillus parasiticus por fermentação em arroz parboilizado, de acordo com o anteriormente descrito (Shotwel et al. 1966).

\section{Bioquímica sérica e métodos em clínica e patologia}

Em ambos os experimentos os animais foram pesados semanalmente para obtenção da média de ganho de peso por dia. Para realização de eritrograma e exames bioquímicos, $10 \mathrm{~mL}$ de sangue foram coletados da jugular de todos os bezerros antes da admi-

Quadro 1. Intoxicação experimental por aflatoxina em bezerros.

Dados dos bovinos utilizados nos dois experimentos, quantidades de toxina fornecida e modo de administração

\begin{tabular}{cccccc}
\hline Bezerro & $\begin{array}{c}\text { Idade } \\
\text { (meses) }\end{array}$ & $\begin{array}{c}\text { Peso inicial } \\
(\mathrm{kg})\end{array}$ & $\begin{array}{c}\text { Peso final } \\
(\mathrm{kg})\end{array}$ & $\begin{array}{c}\text { Dose AFB 1 } \\
(\mathrm{ppb})\end{array}$ & $\begin{array}{c}\text { Modo de } \\
\text { administração }\end{array}$ \\
\hline $1^{\mathrm{a}}$ & 3 & 67.9 & 83.8 & $500 \pm 100$ & MR $^{\mathrm{b}}$ \\
$2^{\mathrm{a}}$ & 3 & 62.5 & 79.7 & $500 \pm 100$ & MR \\
$3^{\mathrm{a}}$ & 4 & 88.1 & 110.2 & $500 \pm 100$ & MR \\
$4^{\mathrm{a}}$ & 3 & 70.5 & 85.6 & $500 \pm 100$ & MR \\
$5^{\mathrm{a}}$ & 4 & 81.9 & 95.8 & $500 \pm 100$ & MR \\
$6^{\mathrm{a}}$ & 3 & 71.9 & 84.4 & $500 \pm 100$ & MR \\
$7^{\mathrm{a}}$ & 4 & 86.1 & 115 & $500 \pm 100$ & MR \\
$8^{\mathrm{a}}$ & 4 & 93.5 & 120.1 & $500 \pm 100$ & MR \\
$9^{\mathrm{a}}$ & 3 & 71.4 & 99.6 & $500 \pm 100$ & MR \\
$10^{\mathrm{ac}}$ & 4 & 82.0 & 111 & 0 & MR \\
$11^{\mathrm{ac}}$ & 2 & 44.5 & 63.7 & 0 & MR \\
$12^{\mathrm{ac}}$ & 4 & 79.9 & 102.3 & 0 & MR \\
$13^{\mathrm{d}}$ & 4 & 92.8 & 107.2 & 1250 & DA \\
$14^{\mathrm{d}}$ & 5 & 135.8 & 135 & 2500 & DA \\
$15^{\mathrm{d}}$ & 5 & 145.8 & 137.6 & 5000 & DA \\
$16^{\mathrm{dc}}$ & 5 & 138.7 & 161 & 0 & DA
\end{tabular}

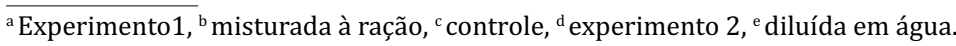


nistração da toxina (dia zero) e nos dias 7, 14, 21, 28, 35, 49 e 63 após o início da ingestão da toxina. Para o eritrograma foram utilizados $5 \mathrm{~mL}$ de sangue acondicionado em tubos com o anticoagulante ácido etilenodiaminotetracético (EDTA). Para realização de exames bioquímicos, que incluíam a determinação da atividade sérica das enzimas aspartato-aminotransferase (AST), gama-glutamiltransferase (GGT) e fosfatase alcalina (FA), e níveis de proteína totais (PT), albumina sérica (AS), billirubina total (BT) e bilirrubina direta (BD), foram utilizados $5 \mathrm{ml}$ de sangue acondicionado em tubos sem anticoagulante. As contagens sanguíneas foram realizadas em contadores celulares automatizados através do princípio da impedância elétrica. Os exames bioquímicos foram realizados sob automatização, por métodos cinéticos (AST e GGT) ou colorimétricos (FA, BT e BD) através de química seca. A análise dos níveis de proteínas totais e albumina no soro foi realizada pelo método de biureto e verde de bromocresol, respectivamente.

Biópsias hepáticas foram realizadas semanalmente, para coleta de amostras destinadas a análise histopatológica. A área escolhida para as punções localizava-se no $11^{\circ}$ espaço intercostal direito cerca de $20 \mathrm{~cm}$ abaixo da linha do dorso, no cruzamento de duas linhas imaginárias: uma da tuberosidade do íleo à escápula e outra perpendicular ao $11^{\circ}$ espaço intercostal. A técnica para punção consistiu de: 1) tricotomia e anti-sepsia da região; 2) anestesia local (pele ao peritônio) com $5 \mathrm{ml}$ de lidocaína a $2 \%$ sem vasoconstritor; 3) perfuração da pele e músculo com agulha $40 \times 20 \mathrm{~mm}$; 4) e punção do fígado utilizando-se uma agulha de Menghini (Barros et al. 2007). Os tecidos obtidos nas biópsias hepáticas e fragmentos de órgãos de um bezerro submetido a eutanásia foram fixados em formol a 10\%, processados e corados pelas técnicas de hematoxilina e eosina.

Os resultados do exames bioquímicos e ganho de peso dos bezerros do primeiro experimentos foram submetidos à análise variância (ANOVA) seguido pelo teste t (Silva \& Azevedo 2002). 0 nível de significância foi fixado em $\mathrm{P}<0.05$.

\section{RESULTADOS}

\section{Sinais clínicos e achados da bioquímica sérica}

Não foram observados sinais clínicos e alterações no ganho de peso (Fig.1) nos nove bezerros que receberam doses diárias de $500 \pm 100 \mathrm{ppb}$ de aflatoxina, durante os 63 dias de experimento e nas avaliações realizadas até três semanas após o término desse período. Nesse primeiro experimento, não foi observada diferença significativa no hematócrito e nos níveis da AS e PT e da atividade sérica de AST durante o período experimental, quando comparados os resultados semanais e quinzenais do Grupo controle e do Grupo tratamento. Esses parâmetros permaneceram dentro dos valores normais de referência, durante todo período experimental, nos bezerros de ambos os grupos. Os níveis das enzimas séricas FA e GGT também foram semelhantes nas aferições semanais para ambos os grupos, durante grande parte do experimento, porém, aumento significativo $(\mathrm{P}<0.05)$ dos níveis dessas enzimas foi observado na última coleta do período experimental (63o dia). Os valores referentes aos eritrogramas e bioquímica sérica dos bezerros do primeiro experimento são demonstrados na Figura 2.

No segundo experimento, sinais clínicos associados à intoxicação foram observados a partir do $10^{\circ}, 23^{\circ}$ e $42^{\circ}$ o dias de experimento, nos bezerros recebendo 5.000, 2.500 e $1.250 \mathrm{ppb}$ de AFB1, respectivamente, e incluíam, inicial- a)

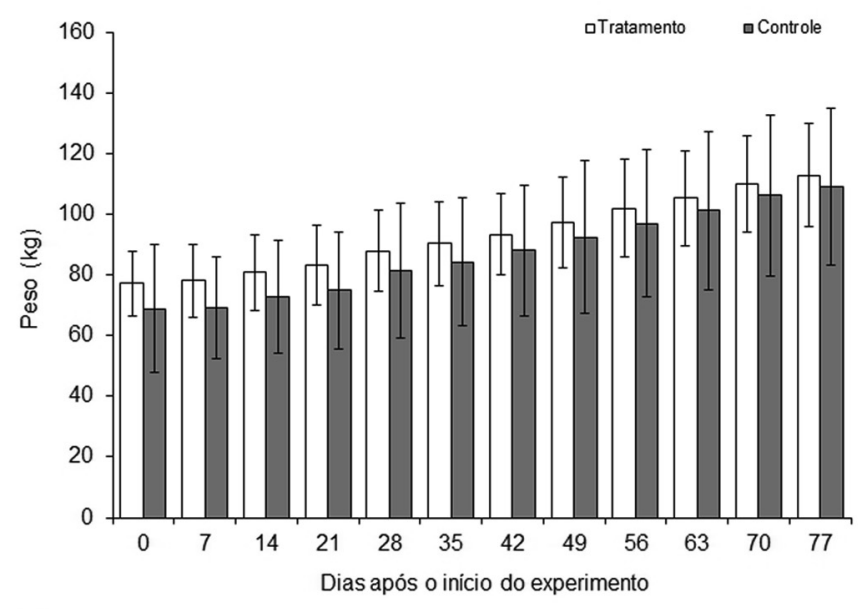

b)

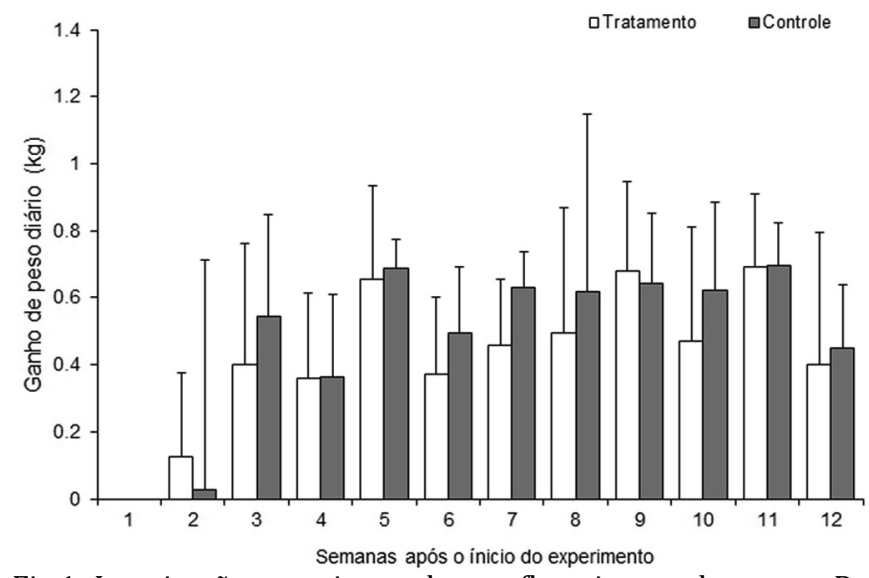

Fig.1. Intoxicação experimental por aflatoxina em bezerros. Representação gráfica do peso médio semanal e ganho de peso semanal dos bezerros dos grupos controle e tratamento do primeiro experimento.

mente, perda de apetite, seguida de diminuição do ganho de peso e emagrecimento (Fig.3). Diminuição do ganho de peso foi avaliada pela comparação do ganho de peso dos bezerros intoxicados com o peso do bezerro controle ou, então, com ganho de peso médio dos bezerros controle do primeiro experimento. Mesmo que oscilações entre ganho e perda de peso tenham sido observadas em todos os bezerros desse segundo experimento, incluindo o animal controle, nas primeiras semanas de ingestão da toxina, a diminuição do ganho de peso dos animais do grupo tratamento foi melhor observada nas pesagens do $14^{\circ}$ e $28^{\circ}$ dias de experimento nos bezerros recebendo $5.000 \mathrm{ppb}$ e $2.500 \mathrm{ppb}$, respectivamente. Esses mesmos bezerros apresentaram acentuada perda de peso nas pesagens do $21^{\circ}$ e $49^{\circ}$ dias de experimento, respectivamente. Sinais clínicos considerados terminais, caracterizados por diarreia (Fig.4A), tenesmo (Fig.4B), icterícia e apatia severa, foram observados apenas no bezerro recebendo $5.000 \mathrm{ppb}$, a partir do $40^{\circ}$ dia de experimento, e foram a razão para eutanásia desse bezerro no $60^{\circ}$ dia de experimento.

Alterações na bioquímica sérica dos bezerros no segundo experimento foram representadas por níveis anormais 
a)

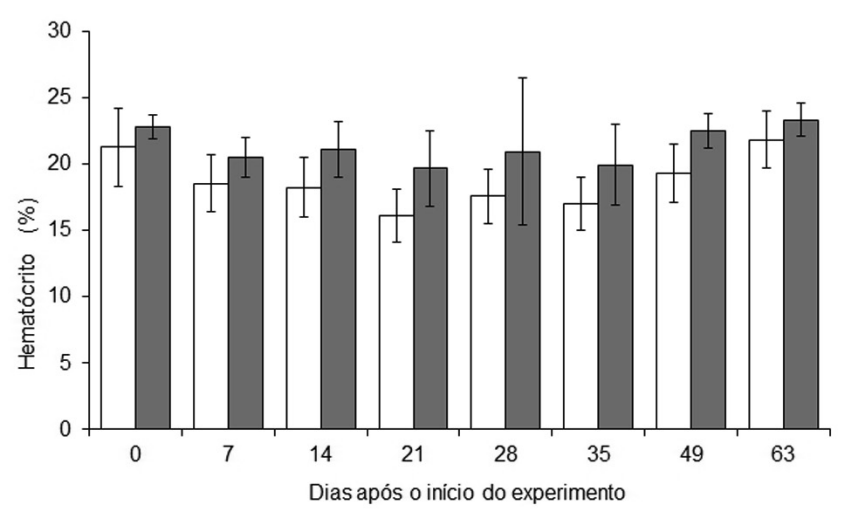

c)

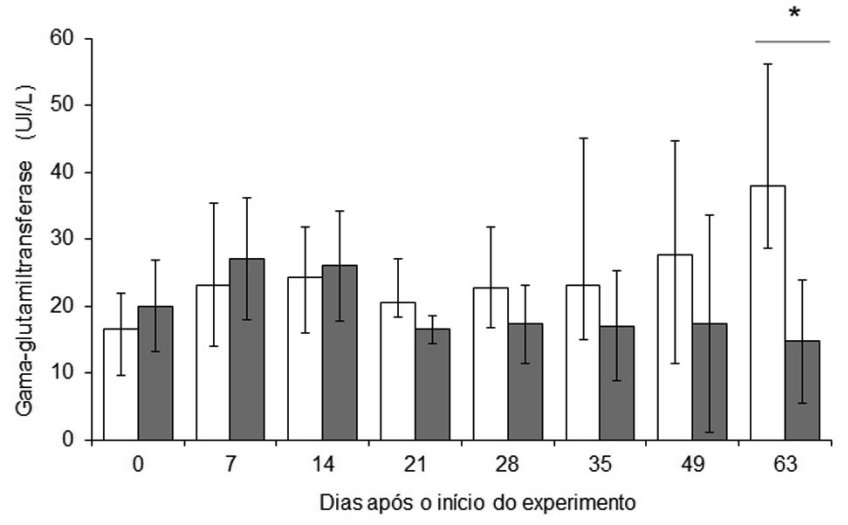

e)

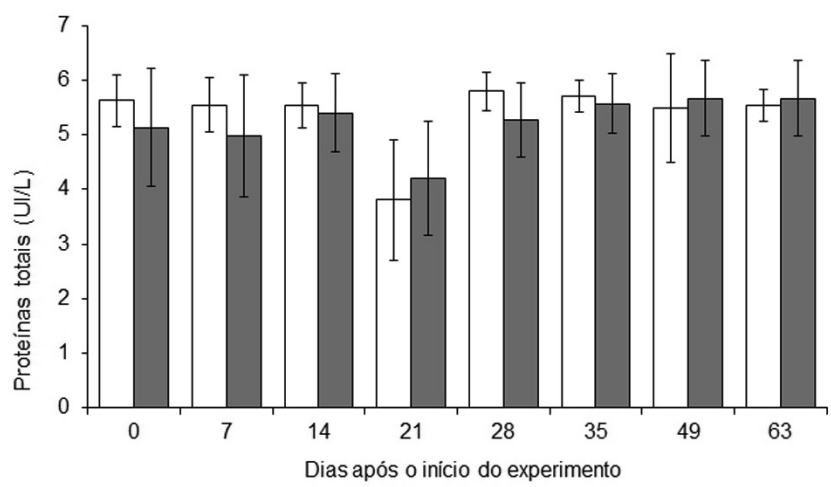

b)

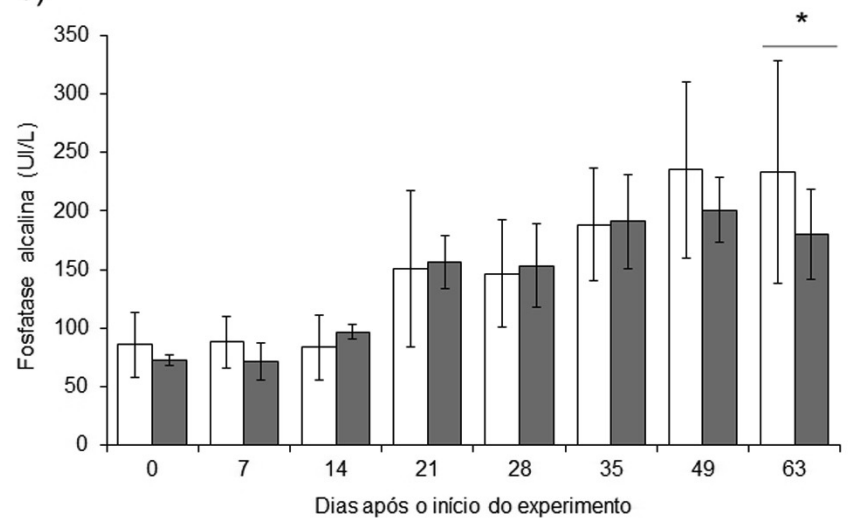

d)

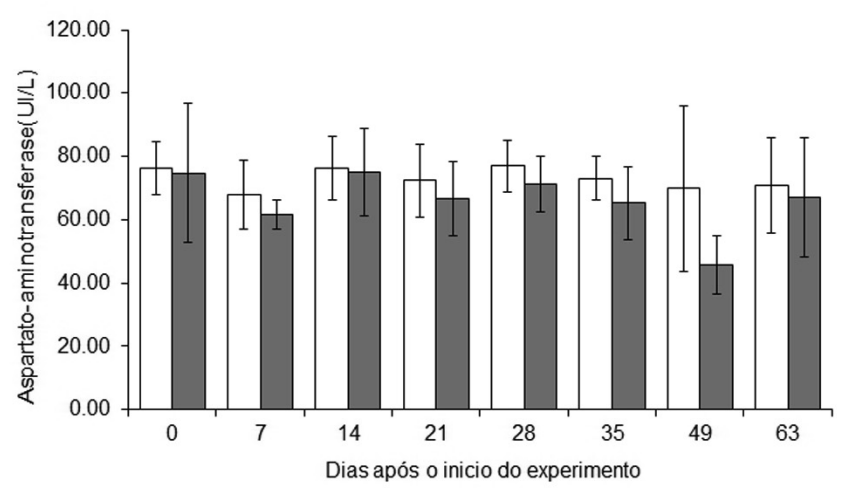

f)

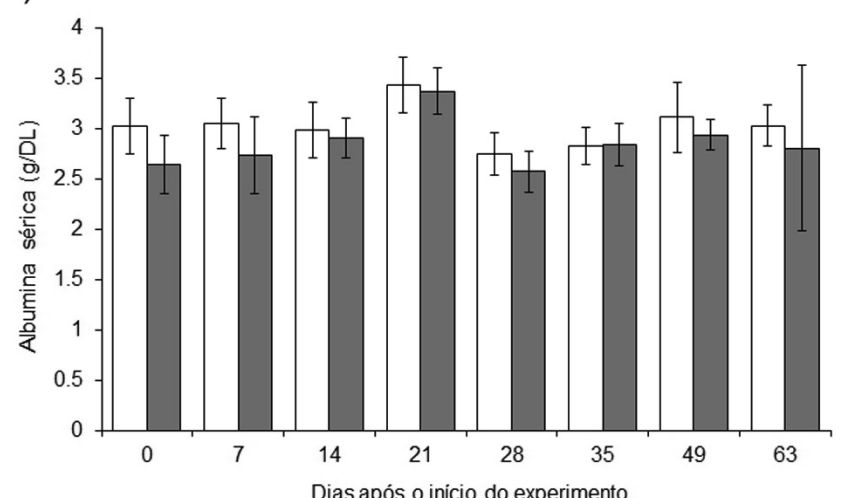

Fig.2. Intoxicação experimental por aflatoxina em bezerros. Representação gráfica do hematócrito e parâmetros da bioquímica sérica dos bezerros dos grupos controle e tratamento do primeiro experimento.

da enzima FA e GGT. Níveis acima dos valores normais de referência para a enzima FA foram observados a partir da coleta do $14^{\circ}$ dia de experimento nos bezerros recebendo 2.500 e 5.000 ppb de AFB1 e 28o dia de experimento no bezerro recebendo $1.250 \mathrm{ppb}$ de AFB1. Níveis anormais da enzima GGT foram observados a partir do $14^{\circ}$ dia de experimento nos três bezerros do grupo tratamento. Os níveis dessas duas enzimas aumentaram gradativamente nas coletas subsequentes até o término do experimento. 0 nível de AS nos bezerros desse experimento permaneceu dentro dos valores normais de referência durante a maior parte do período experimental, porém, na coleta do 49o dia de experimento foi observada queda acentuada do nível des- sa proteína no bezerro recebendo 5.000 ppb de AFB1. Não foram observadas anormalidades no hematócrito e nos níveis da atividade sérica da AST, nem nos níveis de BT, BD e PT desses bezerros, durante todo período experimental. Os valores referentes aos pesos e bioquímica sérica dos bezerros do segundo experimento estão no Quadro 2.

\section{Achados de necropsia e histopatológicos}

Durante todo período experimental, e três semanas após o término do experimento, não foram observadas alterações histopatológicas que pudessem estar associadas à ingestão de aflatoxinas, nas biópsias hepáticas dos bezerros do primeiro experimento. 
Quadro 2. Intoxicação experimental por aflatoxina em bezerros (Experimento 2). Pesagens e achados da bioquímica sérica observados nos três bezerros intoxicados e num bovino controle

\begin{tabular}{|c|c|c|c|c|c|c|c|c|c|c|c|}
\hline \multirow[t]{2}{*}{ Parâmetro } & \multicolumn{11}{|c|}{ Dias de após o início do experimento } \\
\hline & Bov. & 0 & 7 & 14 & 21 & 28 & 35 & 42 & 49 & 56 & 63 \\
\hline \multicolumn{12}{|l|}{ Peso $(\mathrm{kg})^{\mathrm{a}}$} \\
\hline & $1^{\mathrm{b}}$ & 138,7 & 139,5 & 139,4 & 145,5 & 149,2 & 155,5 & 160 & 161 & 163,5 & 165 \\
\hline & $2^{c}$ & 92,8 & 93,5 & 96,5 & 97,1 & 96,9 & 101,5 & 105,7 & 107,2 & 107,2 & 108 \\
\hline & $3^{\mathrm{d}}$ & 135,8 & 136,0 & 135,6 & 137 & 137,2 & 139 & 140,7 & 135 & 134,1 & 133,3 \\
\hline & $4^{e}$ & 143,8 & 144,5 & 144,9 & 141,9 & 141,5 & 141,5 & 141,2 & 137,6 & - & - \\
\hline \multicolumn{12}{|l|}{$\mathrm{FA}^{\mathrm{f}}(0,0-160,0 \mathrm{UI} / \mathrm{L})$} \\
\hline & 1 & 79 & 79 & 97 & 90 & 84 & 91 & 114 & 109 & 98 & - \\
\hline & 2 & 93 & 107 & 136 & 146 & 213 & 293 & 268 & 208 & 269 & - \\
\hline & 3 & 152 & 156 & 189 & 296 & 365 & 427 & 396 & 400 & 307 & - \\
\hline & 4 & 132 & 123 & 164 & 378 & 543 & 568 & 555 & 560 & - & - \\
\hline \multicolumn{12}{|c|}{$\mathrm{GGT}^{\mathrm{g}}(20,0-27,0 \mathrm{UI} / \mathrm{L})$} \\
\hline & 1 & 13 & 12 & 15 & 14 & 18 & 13 & 17 & 16 & 18 & - \\
\hline & 2 & 19 & 19 & 29 & 44 & 93 & 122 & 129 & 101 & 89 & - \\
\hline & 3 & 15 & 23 & 30 & 60 & 157 & 178 & 198 & 211 & 173 & - \\
\hline & 4 & 16 & 22 & 68 & 226 & 340 & 318 & 226 & 200 & - & - \\
\hline \multicolumn{12}{|c|}{$\operatorname{AST}^{\mathrm{h}}(40,0-130,0 \mathrm{UI} / \mathrm{L})$} \\
\hline & 1 & 65 & 51 & 64 & 42 & 56 & 68 & 62 & 68 & 73 & - \\
\hline & 2 & 92 & 97 & 86 & 77 & 76 & 71 & 75 & 85 & 77 & - \\
\hline & 3 & 60 & 70 & 67 & 116 & 98 & 104 & 81 & 71 & 82 & - \\
\hline & 4 & 61 & 79 & 96 & 112 & 90 & 52 & 63 & 69 & - & - \\
\hline \multicolumn{12}{|l|}{$\mathrm{PT}^{\mathrm{i}}(6,7-7,5 \mathrm{UI} / \mathrm{L})$} \\
\hline & 1 & 6,5 & 6,1 & 6,3 & 5,9 & 6,3 & 5,8 & 6,4 & 6,4 & 5,8 & - \\
\hline & 2 & 4,8 & 5,0 & 5,6 & 6,0 & 6,1 & 6,1 & 6,1 & 5,7 & 5,6 & - \\
\hline & 3 & 5,4 & 5,1 & 5,6 & 5,5 & 5,8 & 6,1 & 5,9 & 6,0 & 6,2 & - \\
\hline & 4 & 5,9 & 6,0 & 6,5 & 6,1 & 6,5 & 6,2 & 6,0 & 6,6 & - & - \\
\hline \multicolumn{12}{|l|}{$\operatorname{AS}^{\mathrm{j}}(2,5-3,5 \mathrm{~g} / \mathrm{DL})$} \\
\hline & 1 & 2,6 & 2,5 & 2,6 & 2,4 & 2,4 & 2,4 & 2,6 & 2,7 & 2,6 & - \\
\hline & 2 & 2,5 & 2,8 & 2,7 & 2,6 & 2,6 & 2,8 & 2,8 & 2,7 & 2,6 & - \\
\hline & 3 & 3,0 & 2,5 & 2,9 & 3,1 & 3,0 & 2,8 & 2,8 & 3,0 & 2,8 & - \\
\hline & 4 & 3,0 & 2,9 & 3,0 & 2,8 & 2,8 & 2,7 & 2,5 & 0,4 & - & - \\
\hline \multicolumn{12}{|c|}{$\mathrm{BT}^{\mathrm{k}}(0,01-3,20 \mathrm{mg} / \mathrm{DL})$} \\
\hline & 1 & 1,69 & 1,74 & 1,7 & 1,8 & 1,78 & 1,73 & 1,63 & 1,74 & 1,81 & - \\
\hline & 2 & 1,8 & 1,69 & 1,7 & 1,7 & 1,7 & 1,77 & 1,81 & 1,85 & 1,80 & - \\
\hline & 3 & 1,59 & 1,68 & 1,86 & 1,79 & 1,89 & 1,14 & 1,11 & 1,05 & 1,14 & - \\
\hline & 4 & 1,26 & 1,18 & 1,21 & 1,15 & 1,11 & 1,64 & 1,92 & 2,01 & - & - \\
\hline \multicolumn{12}{|c|}{$\mathrm{BD}^{\mathrm{I}}(0,04-0,44 \mathrm{mg} / \mathrm{DL})$} \\
\hline & 1 & 0,08 & 0,1 & 0,07 & 0,04 & 0,05 & 0,02 & 0,19 & 0,1 & 0,06 & - \\
\hline & 2 & 0,10 & 0,08 & 0,23 & 0,05 & 0,09 & 0,17 & 0,15 & 0,1 & 0,16 & - \\
\hline & 3 & 0,35 & 0,04 & 0,16 & 0,09 & 0,02 & 0,07 & 0,07 & 0,16 & 0,26 & - \\
\hline & 4 & 0,01 & 0,04 & 0,07 & 0,10 & 0,09 & 0,24 & 0,5 & 0,04 & - & - \\
\hline
\end{tabular}

a Os números entre parênteses após o nome do parâmetro são os valores de referência; ${ }^{\mathrm{b}}$ bezerro controle; ${ }^{\mathrm{c}}$ bezerro $1250 \mathrm{ppb}$; ${ }^{\mathrm{d}}$ bezerro $2500 \mathrm{ppb}$; ${ }^{\mathrm{e}}$ bezerro $5000 \mathrm{ppb}$; ${ }^{\mathrm{f}}$ fosfatase alcalina; ${ }^{\mathrm{g}}$ gama glutamil transferase;

${ }^{\mathrm{h}}$ aspartato amino transferase; i proteínas totais; ' albumina sérica; ${ }^{\mathrm{k}}$ billirubina total; ' billirubina direta.

$\mathrm{Na}$ análise histopatológica das biópsias hepáticas dos bezerros do segundo experimento a lesão mais precocemente observada caracterizava-se por macro e microvacúolos intracitoplasmáticos, isolados ou múltiplos (degeneração citoplasmática vacuolar consistente com acumulação hepatocelular de lipídios) principalmente em hepatócitos da região centrolobular. Essa lesão foi observada nas biópsias hepáticas do $14^{\circ}$ dia de experimento no bezerro recebendo 5.000 ppb de AFB1 e 210 dia de experimento nos bezerros recebendo 1.250 e $2.500 \mathrm{ppb}$ de AFB1. No entanto, diminuição da severidade até completo desaparecimento dessas lesões foi observadas nas biópsias das duas semanas subsequentes. Proliferação de ductos biliares foi observada a partir da biópsia hepática realizada no $28^{\circ}$ dia de experimento nos bezerros recebendo 1.250 ppb e 5.000 ppb, e $35^{\circ}$ dia de experimento, no bezerro recebendo $2.500 \mathrm{ppb}$. Inicialmente, essa lesão era observada como pequenos agregados de células cuboidais epiteliais, formando estruturas semelhantes a ductos, frequentemente sem lúmen central, concentrados ao redor de espaços porta. Nas biópsias hepáticas subsequentes essas lesões foram observadas com maior intensidade e frequência, não só em torno de espaços porta, mas estendendo-se para regiões mediozonais. Essas duas lesões foram seguidas por fibrose, observada principalmente ao redor de espaços porta e ductos biliares neoformados, observadas nas biópsias hepáticas coletadas a partir do 35은 $(1.250$ e $5.000 \mathrm{ppb})$ e $42^{\circ}$ dias de experimento ( $2.500 \mathrm{ppb}$ ), além de megalocitose discreta e edema. As biópsias subsequentes revelaram aumento progressivo das áreas de fibrose, principalmente ao redor de espaços porta, com evolução pra fibrose em ponte (Fig.5). Posteriormente ao estabelecimento das áreas de fibrose e proliferação de ductos, principalmente nas últimas biópsias hepáticas de todos os bezerros desse experimen- 


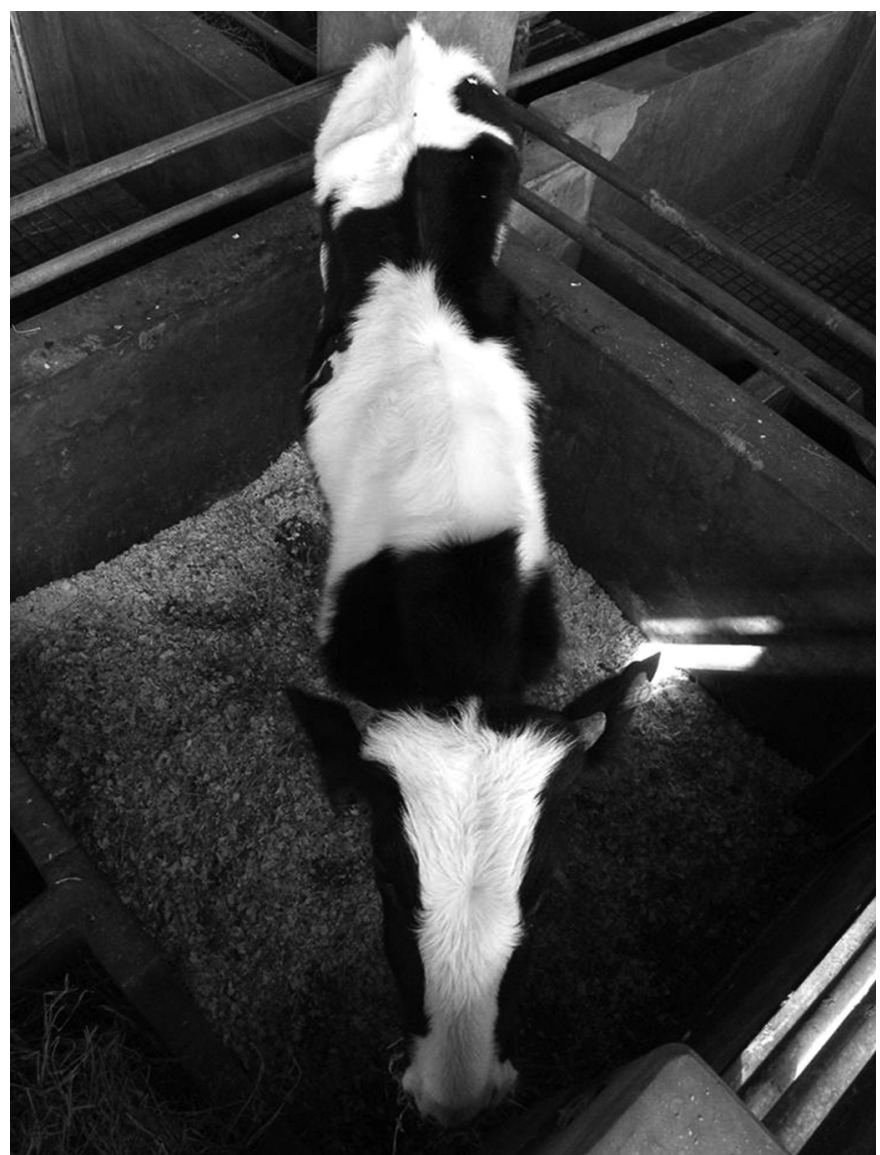

Fig.3. Intoxicação experimental por aflatoxina em bezerro que recebeu a dose de $5.000 \mathrm{ppb}$ de AFB1apresentando baixo escore corporal (2-5), evidenciado por proeminentes ileo, isquio, processos tranverso das vértebras, e reducão das massas musculares dos membros

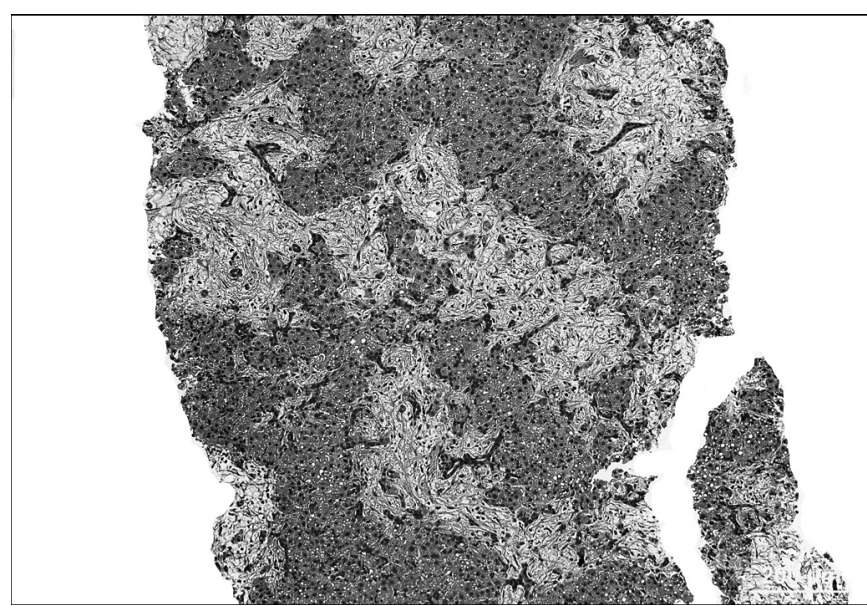

Fig.5. Alterações histológicas na biópsia hepática do $42^{\circ}$ dia de experimento do bezerro que recebeu a dose de $5.000 \mathrm{ppb}$ de AFB1. Observam-se áreas focalmente extensivas de fibrose e proliferação de ductos biliares, concentradas principalmente ao redor de espaços porta e, ocasionalmente, conectando um ducto ao outro. Os feixes de colágeno estão levemente separados por edema. HE, obj.10x.

to, observou-se degeneração citoplasmática hepatocelular vacuolar, consistente com acúmulo de lipídios, ocorrendo em grupos de hepatócitos em meio ao parênquima remanescente.

$\mathrm{Na}$ necropsia do bezerro que recebeu a maior dose de AFB1, observou-se um baixo escore corporal enquadrado no Grau 1 na classificação de estado corporal adotada (Stöber et al. 1990), o que era evidenciado pelo escasso tecido adiposo subcutâneo e abdominal e diminuição do volume das grandes massas musculares dos membros, lombo e quadril. 0 fígado estava levemente aumentado de volume,

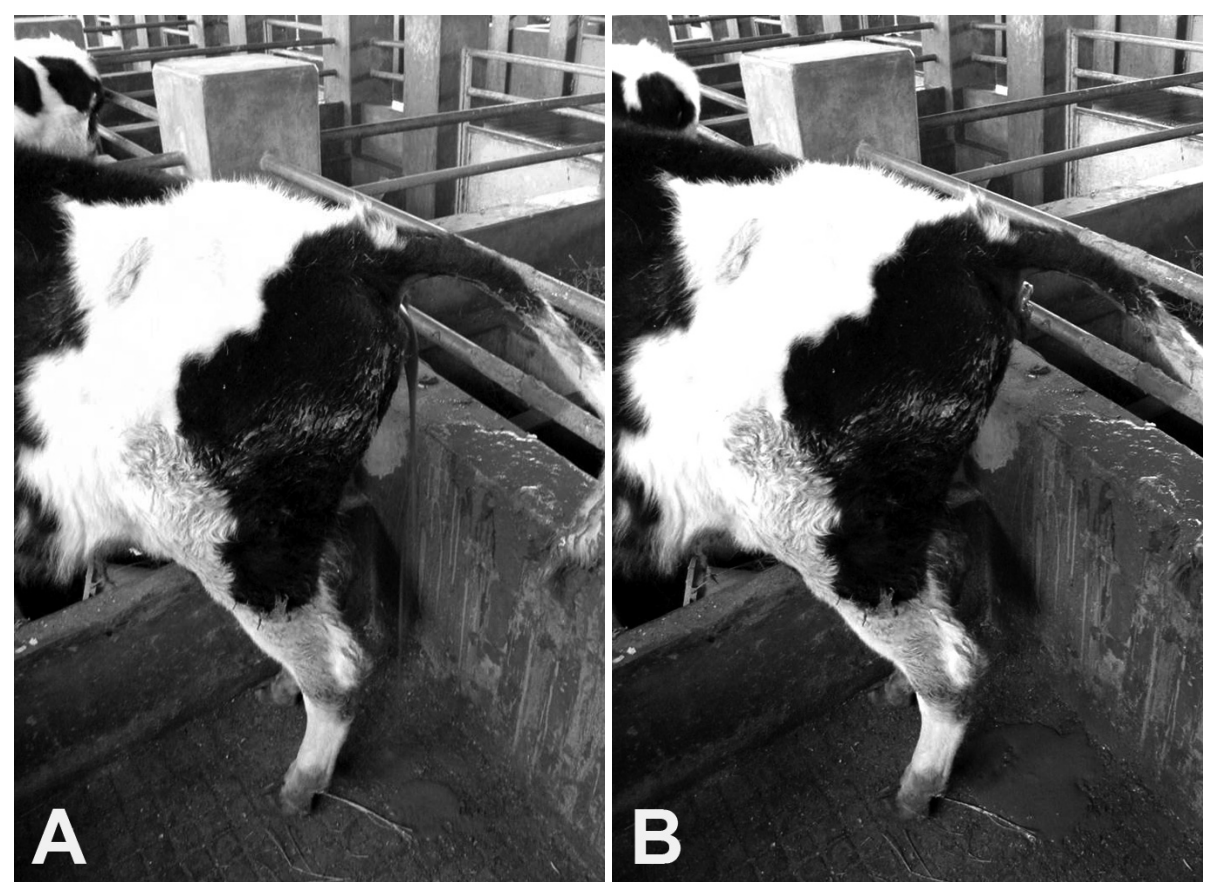

Fig.4. Intoxicação experimental por aflatoxina em bezerros. Sinais clínicos (A) Bezerro que recebeu a dose de $5.000 \mathrm{ppb}$ de AFB1com diarréia liquída e esverdeada. (B) Mesmo bezerro apresentando tenesmo. 
difusamente amarelo-claro e firme (Fig.6 e 7); havia ascite discreta e moderado edema do mesentério e da submucosa do abomaso (Fig.8). A vesícula biliar desse bezerro estava acentuadamente distendida por bile. Histologicamente, a lesão no fígado caracterizava-se por acentuada perda do padrão lobular devido à substituição de aproximadamente metade do parênquima hepático por ductos biliares proliferados, circundados por abundante tecido fibroso, composto por feixes finos de colágeno, arranjados frouxamente e separados por quantidades variáveis de material basofílico pálido homogêneo (edema) (Fig.9 e 10). Esses agregados de tecido fibroso estavam concentrados predominantemente ao redor de espaços porta e, ocasionalmente, conectavam um espaço a outro (fibrose em ponte) (Fig. 9). Múltiplos agregados de hepatócitos apresentando degeneração citoplasmática vacuolar (Fig.11), consistente com acumulação hepatocelular de lipídios, e raros hepatócitos com núcleos aumentados duas a três vezes de tamanho (megalocitose) (Fig.12) eram observados distribuídos aleatoriamente pelo parênquima hepático

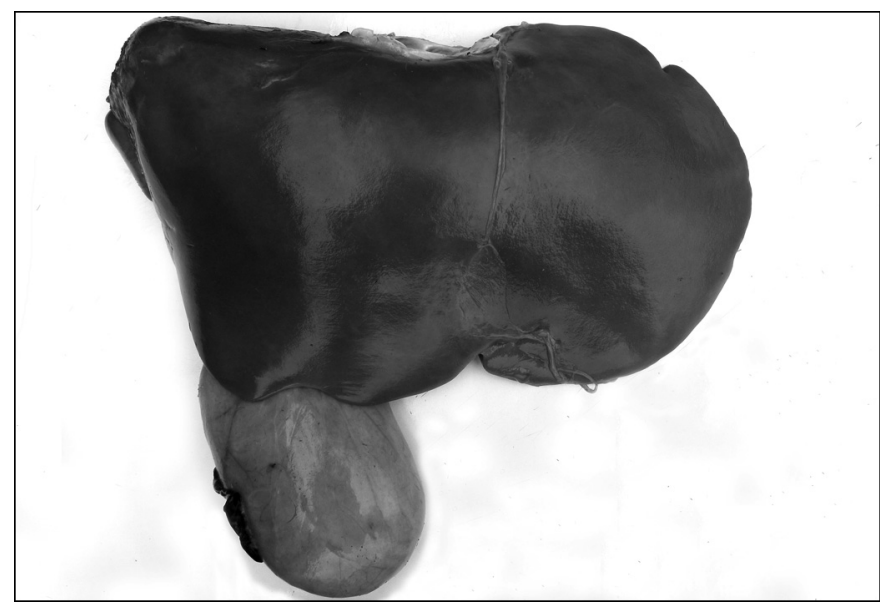

Fig.6. Intoxicação experimental por aflatoxina em bezerros. Que recebeu a dose de 5.000 ppb de AFB1. Observa-se o fígado levemente aumentado de tamanho e difusamente amarelo-claro e firme; a vesícula biliar está acentuadamente distendida por bile.

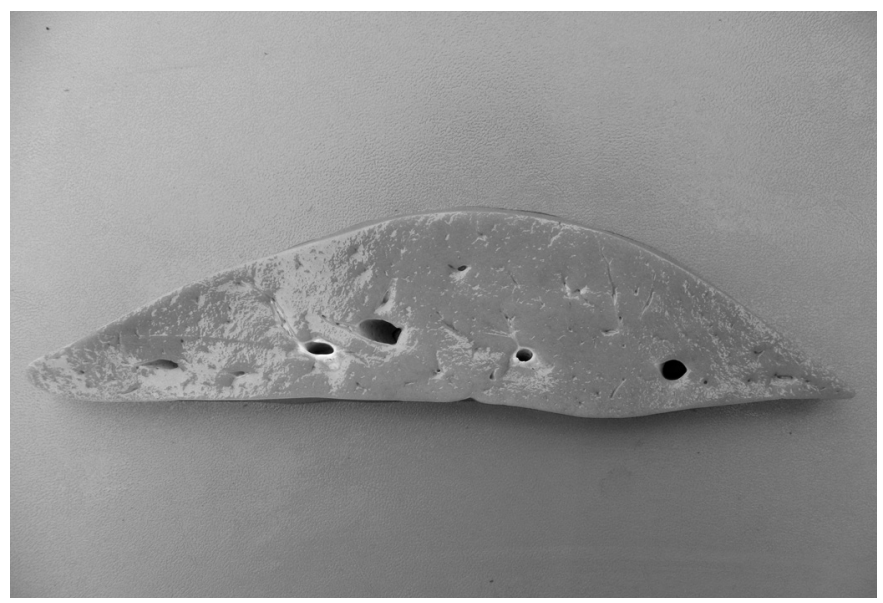

Fig.7. Intoxicação experimental por aflatoxina em bezerros. Que recebeu a dose de 5.000 ppb de AFB1. A superfície de corte está difusamente amarelo-clara.

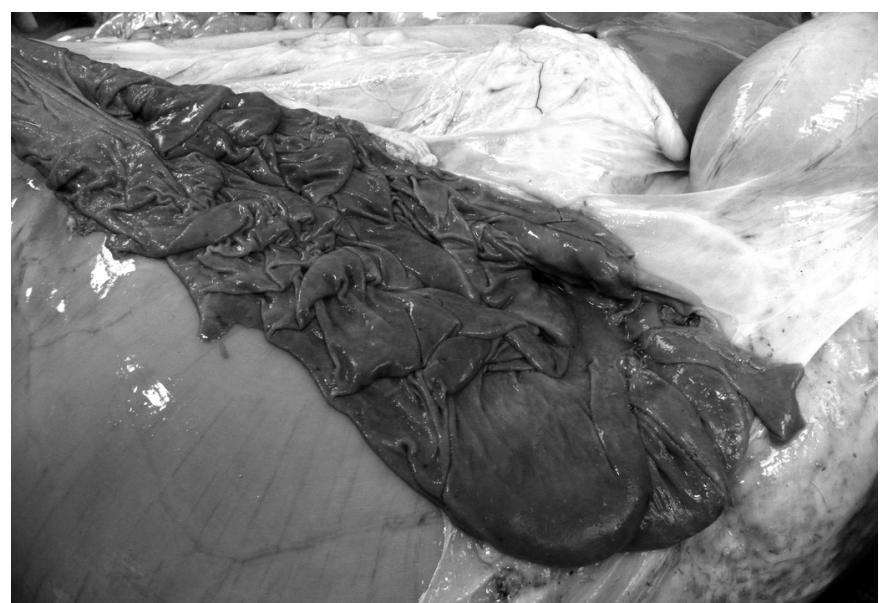

Fig.8. Intoxicação experimental por aflatoxina em bezerro que recebeu a dose de $5.000 \mathrm{ppb}$ de AFB1. Observa-se moderado edema das pregas do abomaso.

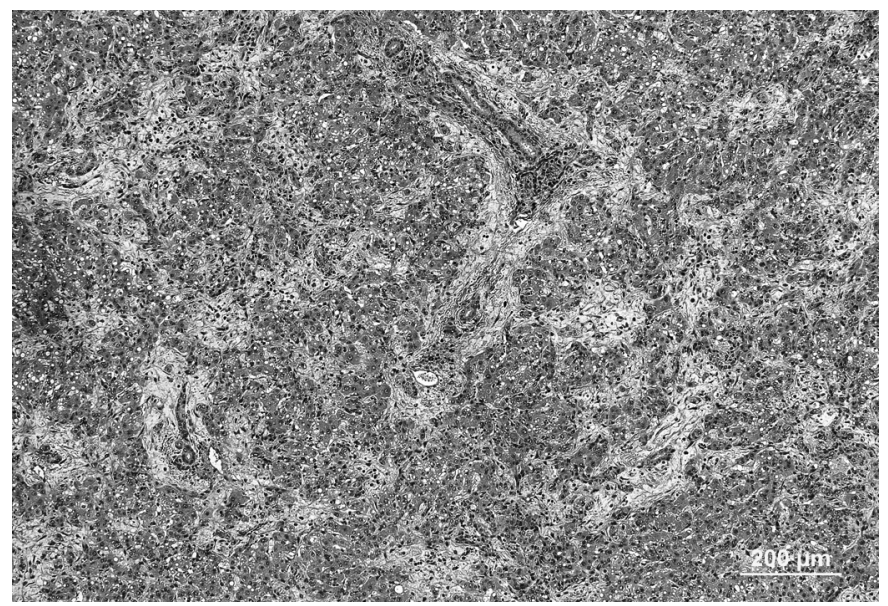

Fig.9. Alterações histológicas no fígado do bezerro que recebeu a dose de 5000 ppb de AFB1. Observam-se áreas focalmente extensivas de fibrose e proliferação de ductos biliares, concentradas principalmente ao redor de espaços porta e, ocasionalmente, conectando um ducto ao outro; os feixes de colágeno estão levemente separados por edema. Numerosos hepatócitos apresentam degeneração citoplasmática vacuolar consistente com acumulação hepatocelular de lipídios em meio ao parênquima remanescente. HE, obj.10x.

remanescente. Lesão venooclusiva incipiente (Fig.13), caracterizada por fibrose leve do espaço subendotelial das veias hepáticas terminais, foi um achado pouco frequente nas biópsias hepáticas desse caso e nas dos demais bezerros intoxicados nesse experimento. Não foram observadas alterações nos demais órgãos e tecidos analisados.

\section{DISCUSSÃO}

O impacto na capacidade produtiva dos animais e as alterações e patológicas descritos em casos naturais e experimentais de aflatoxicose em bovinos foram reproduzidas em três bezerros nesse estudo, demonstrando a susceptibilidade de bovinos nessa faixa etária a doses iguais ou maiores do que $1.250 \mathrm{ppb}$ de AFB1, quando ingeridas diariamente, por um período de até dois meses, semelhantemente ao que é relatado na literatura (Garret et al. 1968, 

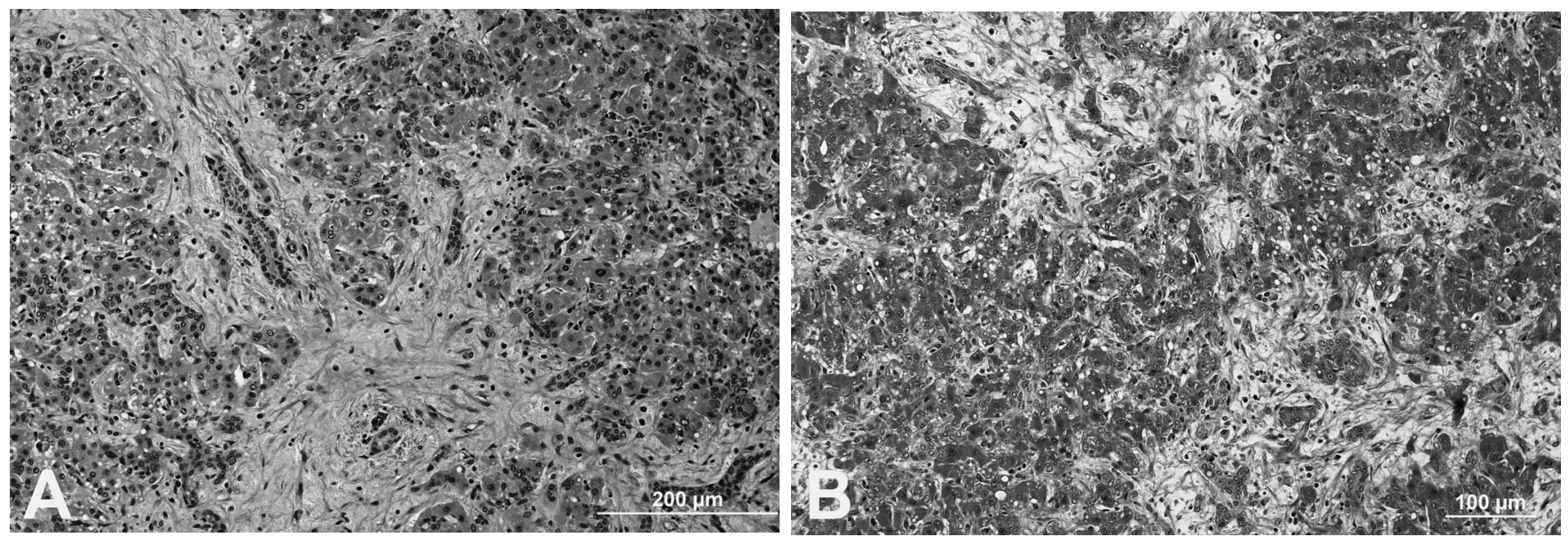

Fig.10. Alterações histológicas no fígado do bezerro que recebeu a dose de 5000 ppb de AFB1. (A) Visão aproximada das lesões descritas na Figura 9. Observam-se as áreas de fibrose e proliferação de ductos biliares, concentradas principalmente ao redor de espaços porta e, ocasionalmente, conectando um ducto ao outro e o material basofílico pálido e homogêneo que separa os feixes de colágeno. HE, obj.20x. (B) Mesma lesão em espécime de fígado corado pelo tricrômico de Masson. Observe a quantidade de feixes de colágenos e a separação entre esses. Obj.20x.

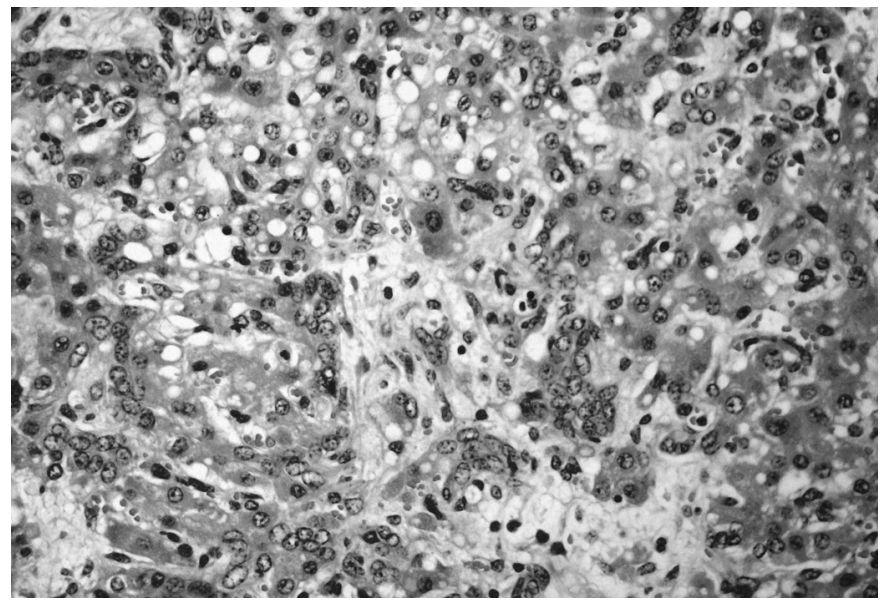

Fig.11. Intoxicação experimental por aflatoxina em bezerro que recebeu a dose de $5.000 \mathrm{ppb}$ de AFB1. Isolados ou múltiplos macro e microvacúolos intracitoplasmáticos (degeneração citoplasmática vacuolar consistente com acumulação hepatocelular de lipídios) em hepatócitos remanescentes, cercados por numerosos ductos biliares neoformados e tecido fibroso. HE, obj.40x.

Keyl \& Booth 1970, Lynch et al. 1970, 1971, Pier et al. 1976, Pedugsorn et al. 1980, Colvin et al. 1984, Osweiller \& Trampel 1985, Hall et al. 1989, Van Halderen et al.1989, Kellerman et al. 2005, D’Angelo et al. 2007, Pierezan et al. 2010). No entanto, bezerros recebendo doses diárias de $500 \pm 100$ ppb de aflatoxina, durante dois meses, não desenvolveram lesões histológicas e sinais clínicos que pudessem estar associadas a ingestão dessa toxina, demonstrando a maior tolerância dos bovinos a essa doses.

A fim de comparar as doses de AFB1 utilizadas em estudos experimentais prévios ou observadas em surtos espontâneos, geralmente expressas em $\mathrm{mg} / \mathrm{kg}$ de peso vivo/dia, às doses utilizadas nesses dois experimentos, essas podem ser apresentadas nessa unidade. No primeiro experimento, no qual a dose utilizada foi de $500 \pm 100$ ppb $(0,5 \pm 0,1 \mathrm{mg}$ de AFB1/kg de ração), esta unidade é obtida pela multiplicação da quantidade de aflatoxina em um quilo ração $(0,5 \pm 0,1 \mathrm{mg})$ pela média da quantidade de ração ingerida diariamente por cada bezerro. Esse resultado é então dividido pelo peso médio de cada bezerro. Dessa forma, estima-se que os bezerros do grupo tratamento, do primeiro experimento, tenham ingerido aproximadamente $0,0075 \mathrm{mg}$ de AFB1 $/ \mathrm{kg}$ p.v./dia. Seguindo o mesmo cálculo, os bezerros do segundo experimento, que recebiam diariamente 1,25, 2,5 e 5,0 $\mathrm{mg}$ de AFB1/kg de ração, ingeriram aproximadamente 0,02, 0,04 e 0,08mg de AFB1/kg p.v./dia, respectivamente.

Se a dose de AFB1 utilizada no primeiro experimento for comparada com doses de AFB1 utilizadas em estudos experimentais prévios será concluído que ela é insuficiente para causar intoxicação em bezerros, pois a menor dose tóxica de aflatoxina, descrita nesses estudos como causa de lesões hepáticas em bovinos, foi de $700 \mathrm{ppb}$. Nesse mesmo artigo, as duas menores doses testadas (100 ppb e $300 \mathrm{ppb}$ ) estavam muito distantes deste valor, deixando dúvidas sobre o possível efeito de doses de 400, 500 e 600 ppb (Keyl

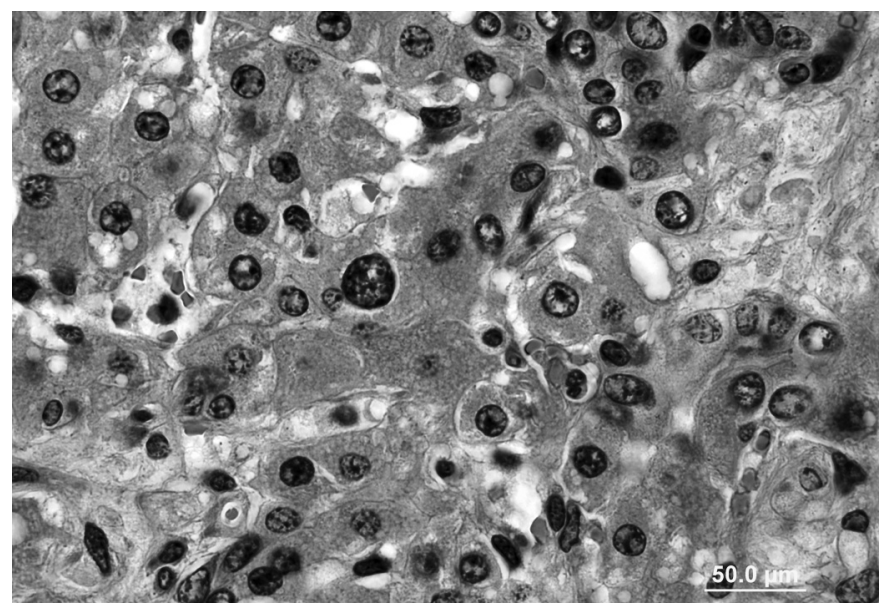

Fig.12. Intoxicação experimental por aflatoxina em bezerro que recebeu a dose de 5000 ppb de aflatoxina B1. Observe no centro da figura um hepatócito com núcleo aumentado duas a três vezes de tamanho (megalocitose). HE, obj.100x. 

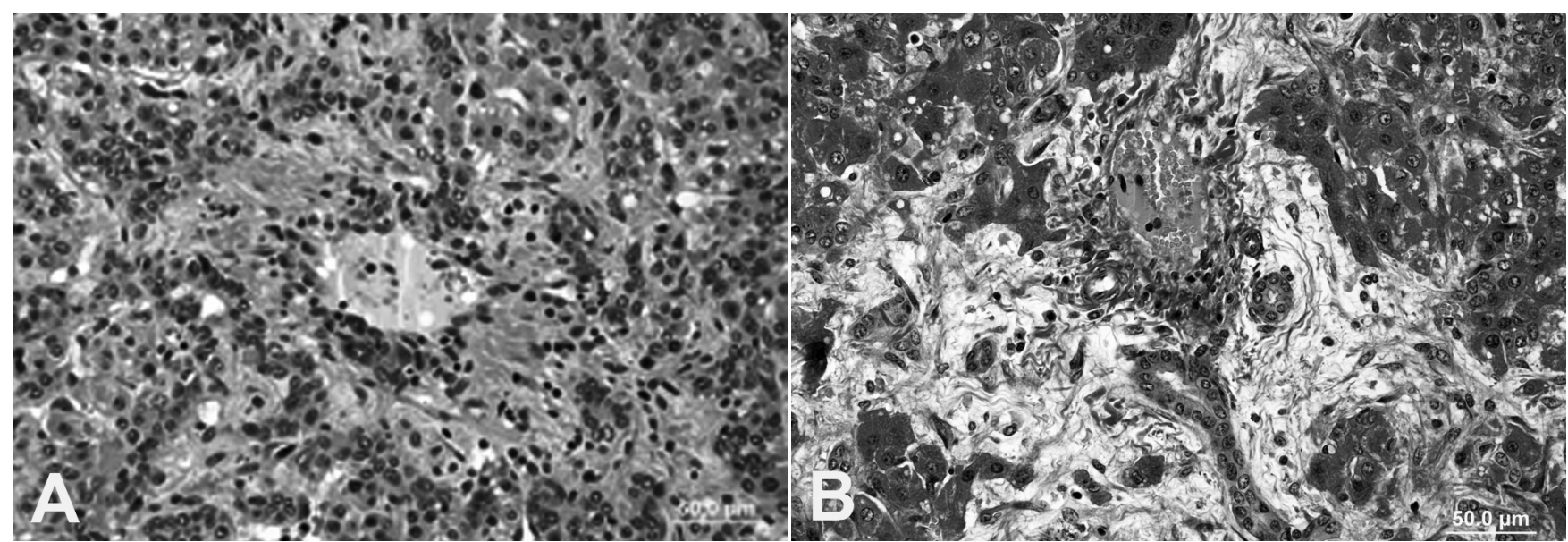

Fig.13. Intoxicação experimental por aflatoxina em bezerro que recebeu a dose de 5000 ppb de AFB1. (A) Lesão venooclusiva incipiente; o espaço subendotelial das veias centrolobulares está levemente distendido tecido fibroso. HE, obj.40x. (B) Mesma lesão em corte de fígado corado pelo tricrômico de Masson, obj.40x.

\& Booth 1970). Outro estudo, incluindo a dose de 0,008mg de AFB1/kg p.v./dia, não pode demonstrar os efeitos da mesma em bezerros, pois os dois animais testados morreram nas primeiras semanas de experimento de causas não relacionadas à ingestão da toxina (Lynch et al. 1970). No entanto, em surtos espontâneos de aflatoxicose em bovinos, doses de $50 \mathrm{a} 200 \mathrm{ppb}$, têm sido relacionadas à doença hepática crônica (Dutra et al. 2011) ou aguda (McKenzie et al. 1981), respectivamente. Os resultados obtidos em nosso primeiro experimento, não puderam confirmar esses dados e indicam que doses de 50 a $200 \mathrm{ppb}$, assim como as demais doses abaixo de $500 \pm 100$ ppb de AFB1, não são suficientes para produzir a lesão hepática, aguda ou crônica, sequer em bezerros. Por outro lado, doses semelhantes às utilizadas no segundo experimento são comprovadamente tóxicas para bovinos jovens e causam sinais clínicos e lesões semelhantes às descritas nesse experimento, tanto em condições experimentais (Garret et al. 1968, Keyl \& Booth 1970, Lynch et al. 1970), como naturais (Pedugsorn et al. 1980, Colvin et al. 1984, Osweiller \& Trampel 1985, Hall et al. 1989, D'Angelo et al. 2007). No entanto, uma dose maior $(0,1 \mathrm{mg} / \mathrm{kg}$ p.v/dia) do todas as doses aqui testadas já foi descrita como não tóxica para bovinos (Pier et al. 1976). A maior dose testada nos experimentos descritos aqui (5.000 ppb) foi idêntica a dose estimada em um surto espôntaneo observado nesse laboratório e previamente descrito pelos autores (Pierezan et al. 2010). Através dos resultados aqui obtidos, comprovou-se não apenas o envolvimento dessas toxinas com esse surto, devido à semelhança dos achados clínicos e patológicos em ambos os casos, mas também o alto efeito tóxico dessa dose para bovinos nessa faixa etária.

Não foram observados sinais clínicos que pudessem estar associados à ingestão de aflatoxinas nos bezerros do primeiro experimento, durante todo período experimental e três semanas após o término desse período. Os bezerros deste experimento, que receberam 0,0075mg de AFB1/kg p.v./dia, apresentaram apetite normal durante todo período experimental e ingeriram quantidades crescentes de ração, considerando-se que esse volume foi ajustado semanalmente conforme o peso dos animais, diferentemente de outro estudo experimental, no qual doses equivalentes a 0,008mg de AFB1/kg p.v./dia, misturadas a ração, induziram perda de apetite dos animais já nas primeiras semanas de experimento (Lynch et al. 1970).

Os sinais clínicos observados nos bezerros do segundo experimento, caracterizados por perda de apetite, diminuição do ganho de peso e emagrecimento, mesmo que inespecíficos, são descritos na grande maioria dos casos naturais e experimentais de aflatoxicose em bezerros (Garret et al. 1968, Keyl \& Booth 1970, Lynch et al. 1970, 1971, Pier et al. 1976, Pedugsorn et al. 1980, Colvin et al. 1984, Osweiller \& Trampel 1985, Van Halderen et al. 1989, D’Angelo et al. 2007, Pierezan et al. 2010, Dutra et al. 2011). Nesse experimento, o início e a evolução dos sinais clínicos variaram conforme a quantidade de toxina administrada. Perda de apetite, o sinal clínico mais precoce nesse experimento, foi observado no $10^{\circ}$ dia de experimento no bezerro recebendo a maior dose, enquanto que, para menor dose tóxica testada, esse sinal foi observado 42 dias após o início da ingestão da toxina. Como discutido anteriormente, esse sinal já foi descrito em bezerros nas duas primeiras semanas de ingestão da toxina misturada à ração, mesmo quando testadas doses menores (Lynch et al. 1970), porém, em um estudo onde toxina foi administrada separadamente, o início desse sinal clínico foi semelhante ao observado nesse experimento, principalmente nas doses de 0,08 e $0,1 \mathrm{mg} / \mathrm{kg}$ p.v./dia (Lynch et al. 1971). Diminuição do ganho de peso e emagrecimento, comumente descritos em casos de aflatoxicose em bezerros, podem estar associados tanto com a ação direta das aflatoxinas aos hepatócitos, causando inibição da produção de proteínas pelo fígado, bem como pela diminuição do consumo de alimento, devido à perda de apetite (Lynch et al. 1970).

Sinais clínicos considerados terminais em casos de aflatoxicose, como icterícia e diarreia intermitente (Colvin et al. 1984, Van Halderen et al.1989, Kellerman et al. 2005) foram observados apenas no bezerro recebendo a dose de $5.000 \mathrm{ppb}$ e estavam associados diretamente à lesão hepática crônica. Não foram observados sinais neurólogicos dos bezerros desse experimento, apesar desses sinais já 
terem sido descritos em casos de aflatoxicose em bezerros, associados à encefalopatia hepática (D’Angelo et al. 2007). Hemorragias associadas a distúrbios da hemostasia, comumente observada em casos de aflatoxicose em cães (Newman et al. 2007), não foram observadas nos bezerros desse experimento.

Alterações bioquímicas nos casos de aflatoxicose são representadas principalmente pelo aumento da atividade sérica das enzimas FA e GGT (Garret et al. 1968, Keyl \& Booth 1970, Lynch et al. 1970), como observado principalmente nos bezerros do segundo experimento. A alteração nos níveis de FA e GGT demonstra lesão hepática primária caracterizada por proliferação de ductos biliares e lesão direta aos hepatócitos, respectivamente, o que pode ser comprovado nesse experimento pois o aumento da atividade sérica dessas enzimas seguiu o aparecimento dessas lesões nas biópsias hepáticas. No primeiro experimento, o nível sérico dessas enzimas foi semelhante nos bezerros do grupo controle e tratamento durante a maior parte do período experimental até a última coleta do experimento. 0 nível da FA, em ambos os grupos, esteve acima dos valores normais de referência a partir da coleta do $35^{\circ}$ de experimento, enquanto que o nível da GGT, também nesses dois grupos, esteve acima dos valores normais de referência a partir da coleta do 49o dia de experimento. No entanto, durante todo período experimental, não foram observadas lesões histológicas associadas à ingestão da toxina, que justificassem o aumento da atividade sérica dessas enzimas. Dessa forma, a variação dos níveis dessas enzimas não pode ser esclarecida nesse experimento.

A diminuição acentuada nos níveis de albumina sérica, observada na coleta do 49ำ dia de experimento, no bezerro recebendo $5.000 \mathrm{ppb}$ poderia estar relacionada tanto com a ocorrência de diarreia nesse animal dias antes dessa coleta, como com a diminuição da síntese dessa proteína, devido à lesão hepática crônica. 0 hematócrito e os níveis da enzima sérica AST, bem como de BT, BD e PT permaneceram inalterados durante todo período experimental nos bezerros intoxicados no segundo experimento. Embora alguns estudos demonstrem um aumento nos níveis da AST em casos de aflatoxicose (Pier et al. 1976, D’Angelo et al. 2007), outros estudos demonstram que os níveis dessa enzima (Garret et al. 1968, Keyl \& Booth 1970), bem como das proteínas totais e da albumina permanecem inalterados nos casos dessa doença em bovinos (Lynch et al. 1970, Van Halderen et al. 1989). Dessa forma, esses parâmetros aparentam não ser confiáveis para o diagnóstico clínico dessa doença.

O fígado é o órgão alvo nos casos de intoxicação por aflatoxinas em animais (Kellerman et al. 2005). Lesões macroscópicas nesses casos, são caracterizadas por alteração da cor e tamanho do órgão, devido à substituição do parênquima hepático principalmente por ductos biliares proliferados e degeneração citoplasmática vacuolar consistente com acumulação hepatocelular de lipídios, que, em associação com edema, geralmente provocam leve aumento de volume do órgão (Garret et al. 1968, Keyl \& Booth 1970, Pedugsorn et al. 1980, Osweiller \& Trampel 1985, D’Angelo et al. 2007), como observado na necropsia do animal re- cebendo 5.000 ppb. As demais alterações macroscópicas observadas nesse caso foram secundárias a lesão hepática crônica. Dessa forma, edema observado na submucosa e serosa do trato gastointestinal ou na forma de ascite, esteve relacionado tanto com hipoproteinemia (hipoalbuminaemia), como elevação da hipertensão portal devido à fibrose incipiente ao redor de veias hepáticas terminais.

A biópsia hepática demonstrou que pode ser um método auxiliar no diagnóstico da doença pré-clínica, pois lesões iniciais, caracterizadas por degeneração citoplasmática vacuolar consistente com acumulação hepatocelular de lipídios e proliferação de ductos biliares, puderam ser percebidas nas biópsias antes do aparecimento dos sinais clínicos. Essas duas lesões, em conjunto com fibrose, aparentam ser os principais achados histológicos em casos de aflatoxicose em bovinos. No entanto, na maioria dos casos de aflatoxicose, fibrose ocorre em grau leve a moderado, variando conforme a cronicidade das lesões, e megalocitose é um achado infrequente (Hill 1963, Lynch et al. 1970, 1971, Pier et al. 1976, Colvin et al. 1984, Osweiller \& Trampel 1985).

Esses achados histológicos podem contribuir para o diagnóstico diferencial entre aflatoxicose e intoxicacão por alcaloides pirrolizidinicos, associados principalmente à ingestão de plantas do gênero Senecio. Embora as lesões nessas duas doenças sejam muito semelhantes, a lesão hepática em bovinos intoxicados por alcaloides pirrolizidinicos é caracterizada principalmente pela presença de fibrose, megalocitose e proliferação de ductos biliares biliar, mesmo que, nessa doença diferentes padrões, com variações na distribuição e quantidade dessas lesões, possam ser observados (Grecco et al. 2010). Aparentemente, nos casos de aflatoxicose, a distribuição e quantidade de ductos biliares proliferados e degeneracão vacuolar consistente com acumulação hepatocelular de lipídios é maior do que nos casos de intoxicacão por alcaloides pirrolizidinicos (Dutra et al. 2011), ao contrário da quantidade de fibrose e megalocitose, que aparentam ser menores na maioria dos casos de aflatoxicose . Lesão venooclusiva, comumente descritas em casos de aflatoxicose (Lynch et al. 1970, 1971, Colvin et al. 1984, Hall et al. 1989, Pierezan et al. 2010), e seneciose (Stalker \& Hayes 2007) foi discreta nos bezerros desse experimento, provavelmente devido ao curto tempo de ingestão da toxina.

Concluindo, esse estudo demonstra que doses diárias de 1.250 ppb, 2.500 ppb e 5.000 ppb de aflatoxina B1, em condições experimentais, são tóxicas para bovinos jovens, produzindo sinais clínicos antes do fim do primeiro mês, quando utilizadas as doses mais altas, e lesão hepática crônica, em menos de dois meses de ingestão da toxina, quando utilizadas as três doses testadas. Porém, bezerros ingerindo doses menores ou iguais a $500 \pm 100$ ppb de AFB1 não desenvolvem achados patológicos característicos da doença, mesmo após um período de dois meses de ingestão da toxina, mas podem apresentar mínimas alterações bioquímicas a partir da metade do segundo mês.

Agradecimentos.- À doutora Raquel Rubia Rech pelo auxílio na confecção das fotografias das lesões histológicas. 


\section{REFERÊNCIAS}

Allcroft R. \& Lewis G. 1963. Groundnut toxicity in cattle: Experimental poisoning of calves and report on clinical effects in older cattle. Vet. Rec. 75:487-493.

Barros C.S.L., Castilhos L.M., Rissi D.R., Kommers G.D. \& Rech R.R. 2007. Biópsia hepática no diagnóstico da intoxicação por Senecio brasiliensis em bovinos. Pesq. Vet. Bras. 7:53-60.

Colvin B.M., Harrison L.R., Gosser H.S. \& Hall R.F. 1984. Aflatoxicosis in feeder cattle. J. Am. Vet. Med. Assoc. 184:956-958.

D’Angelo A., Bellino C., Alborali G.L., Biancardi A., Borrelli A., Capucchio M.T., Catalano D., Dellaferrera G., Maurella C. \& Cagnasso A. 2007. Neurological signs associated with aflatoxicosis in Piedmontese calves. Vet. Rec. 160:698-700.

Dutra F. 2011. Enfermedades diagnosticadas. Archivo Veterinario Del Este 3:4-12.

Garret W.N., Heitman H. \& Booth A.N. 1968. Aflatoxin toxicity in beef cattle. Proc. Soc. Exp. Biol. Med. 127:188-190.

Grecco F.B., Schild A.L., Soares M.P., Marcolongo-Pereira C., Estima-Silva P. \& Sallis E.S.V. 2010. Aspectos epidemiológicos e padrões de lesões hepáticas em 35 surtos de intoxicação por Senecio spp. em bovinos no sul do Rio Grande do Sul. Pesq. Vet. Bras. 30(5):389-397.

Hall R.F., Harrison L.R. \& Colvin B.M. 1989. Aflatoxicosis in cattle pastured in a field of sweet corn. J. Am. Vet. Med. Assoc.194:938.

Hill K.R. 1963. Comment on the histological appearances in serial liver biopsies and post-mortem specimens. Vet. Rec. 75:493-494.

Hussein H.S. \& Brasel J.M. 2001. Toxicity, metabolism, and impact of mycotoxins on humans and animals. Toxicology 167:101-134.

Kellerman T.S., Coetzer J.A.W., Naudé T.W. \& Botha C.J. 2005. Plant Poisonings and Mycotoxicoses of Livestock in Southern Africa. $2^{\text {nd }}$ ed. Oxford University Press, Oxford, p.3-6.

Keil A.C. \& Booth A.N. 1971. Aflatoxin Effects in Livestock. J. Am. Oil Chem. Soc. 48:559-604.

Lafluf O., Termezana A., Rivero R., Riet Alvariza F., Feed O., Féola R., Diaz L., Gimenz G., Varela A., Camino A. \& Uriarte G. 1989. Um caso de aflatoxicose em bovinos asociado a maiz carbonoso. 17로 Jornadas Uruguayas de Buiatria, Pasandú, Uruguai, Seção cc 8, p.1-8.

Lynch G.P., Todd G.C., Shalkop W.T. \& Moore L.A. 1970. Responses of dairy calves to aflatoxina-contaminated feed. J. Dairy Sci. 53:63-71.

Lynch G.P., Shalkop W.T., Jakoby N.M., Smith D.F. \& Miller R.W. 1971. Responses of dairy calves to oral doses of aflatoxin. J. Dairy Sci. 54:16881698.

McKenzie R.A., Blaney B.J., Connole M.D. \& Fitzpractick A. 1981. Acute aflatoxicosis in cattle fed peanut hay. Aust. Vet. J. 57:284-286.
Newman S.J., Smith J.R., Stenske K.A., Newman L.B., Dunlap J.R., Imerman P.M. \& Kirk C.A. 2007. Aflatoxicosis in nine dogs after exposure to contaminated commercial dog food. J. Vet. Diag. Invest. 19(2):168-175.

Osweiller G.D. \& Trampel D.W. 1985. Aflatoxicosis in feedlot calves. J. Am. Vet. Med. Assoc. 6:636-637.

Patterson D.S.P. \& Anderson P.H. 1982. Recent aflatoxin feeding experiments in cattle. Vet. Rec. 110: 60.

Pedugsorn C., Promma S., Ratanacchot P. \& Rietschel W. 1980. Chronic aflatoxicosis in cattle on an animal breeding station in North Thailand. Anim. Res. Development 11:106-111.

Pier A.C., Cysewski S.J., Richard J.L., Baetz A.L. \& Mitchell L. 1976. Experimental mycotoxicosis in calves with aflatoxin, ochratoxin, rubratoxin and T-2 toxin. Proc. 80 ${ }^{\text {th }}$ Ann. Meeting U.S. Anim. Health Assoc., p.130148.

Pierezan F., Oliveira Filho J.C., Carmo P.M., Lucena R.B., Rissi D.R., Togni M. \& Barros C.S.L. 2010. Surto de aflatoxicose em bezerros no Rio Grande do Sul. Pesq. Vet. Bras. 30(5):418-422.

Richard J.L., Pier A.A., Stubblefield R.D., Shotwell O.L., Lyon R.L. \& Cutlip R.C. 1983. Effect of feeding corn naturally contaminated with aflatoxin on feed efficiency, on physiologic, immunologic, and pathologic changes, and on tissues residues in steers. Am. J. Vet. Res. 44:1294-1299.

Sastry G.A., Narayana J.V., Rama Rao P., Cristopher J. \& Hill K. 1965. A report on the groundnut toxicity in Murrah buffaloes in Andra Pradesh (India). Indian Vet. J. 42:79.

Silva F.A.S. \& Azevedo C.A.V. 2002. Versão do programa computacional Assistat para o sistema operacional Windows. Revta Bras. Prod. Agroindustr. 4(1):71-78.

Stalker M.J. \& Hayes M.A. 2007. Liver and biliary system, p.297-388. In. Maxie M.G. (Ed.), Jubb, Kennedy, and Palmer's Pathology of Domestic Animals. Vol.2. $5^{\text {th }}$ ed. Saunders Elsevier, Philadelphia.

Shotwel O.L., Hesseltine C.W., Stubblefield R.D. \& Sorenson W.G. 1966. Production of aflatoxin on rice. American Society for Microbiology, Michigan, 14(3):428-429.

Stöber M. 1990. Identificação, anamnese, regras básicas da técnica de exame clínico geral, p.44-80. In: Dirksen G., Gründer H.-D. \& Stöber M. (Eds), Rosenberger Exame Clínico dos Bovinos. $3^{\underline{a}}$ ed. Guanabara-Koogan, Rio de Janeiro.

Vaid J., Dawra R.K., Sharma O.P. \& Negi S.S. 1981. Chronic aflatoxicosis in cattle. Vet. Human Toxicol. 23:436-438.

Van Halderen A., Green J.R., Marasas W.F.O., Thiel P.G. \& Stockenstrom S. 1989. A field outbreak of chronic aflatoxicosis in dairy calves in the Western Cape Province. J. South Afr. Vet. Assoc. 60:210-211.

Yiannikouris A. \& Jouany J. 2002. Mycotoxins in feeds and their fate in animals: A review. Anim. Res. 51:81-99. 